\title{
Rapid turbidimetric assay for quantification of fusidic acid in a dermatological cream
}

\author{
Mariane Machado Curbete*, Hérida Regina Nunes Salgado \\ School of Pharmaceutical Sciences, UNESP-Univ Estadual Paulista, Campus Araraquara, Department of Pharmaceuticals, Rodovia Araraquara-Jaú, km 1, CEP: \\ 14800-903 Araraquara, São Paulo, Brazil
}

\section{A R T I C L E I N F O}

\section{Article history:}

Received 24 November 2015

Received in revised form

29 January 2016

Accepted 30 January 2016

Available online 27 February 2016

Keywords:

Antibiotic

Fusidic acid

Quality control

Turbidimetric assay

Validation

\begin{abstract}
A B S T R A C T
Fusidic acid is an antibiotic steroid widely used for the treatment of serious infections caused by methicillin-resistant Staphylococcus aureus (MRSA) strains. Microbiological methods are indispensable to determine the mean percentage of antimicrobial in medicaments during manufacturing and quality control processes. The aim of this study was to develop and validate a microbiological method for the quantification of fusidic acid in dermatological cream by turbidimetry, using Staphylococcus epidermidis (ATCC 12228) and casoy broth as the culture medium. The validation parameters were in accordance with ICH specifications and demonstrated accuracy, precision, selectivity, and robustness, with linear ranges from 0.25 to $2.25 \mu \mathrm{g} \mathrm{mL}^{-1}$. This method is an alternative to the diffusion agar assay currently employed to quantify fusidic acid in dermatological cream, since it is sensitive, fast, and more economical.
\end{abstract}

(c) 2016 Elsevier B.V. All rights reserved.

\section{Introduction}

Fusidic acid (FA) is an antibiotic produced from the fungus Fusidium coccineum and belongs to the class of steroids [1] (Fig. 1); however, it does not exert effects associated with steroids [2]. It has been widely used to treat infections caused by methicillinresistant Staphylococcus aureus (MRSA) strains [3,4], and it is also effective against other species of Gram-positive bacteria [5,6].

Several physicochemical methods have been described in the literature for the analysis of FA in different matrices, such as spectrophotometry [7-9], electrophoresis [10], electrospray ionization tandem mass spectrometry (ESI-MS) [11], atomic absorption spectroscopy [12], thin-layer chromatography [13-15], highperformance liquid chromatography [13,14,16-27], and surfactant-dye binding degree method [28]. These methods are widely used to evaluate antimicrobial agents, and although precise, cannot represent the true biological activity of a drug.

For this reason, microbiological methods, which are more time consuming, are essential and indispensable for determining the mean percentage of antimicrobial in medicaments during manufacturing and quality control processes, as shown by studies conducted by our research group. In addition, microbiological assays do not require specialized equipment and no toxic solvents are involved [29,30].

\footnotetext{
* Corresponding author.

E-mail address: mari_curbete@hotmail.com (M.M. Curbete).
}

Official compendia generally describe two methods for assessing the mean percentage of antibiotics: turbidimetric method and agar diffusion method [31,32]. Some studies have determined FA in different matrices using agar diffusion [27,33-35]. However, the use of the turbidimetric assay method for this purpose has not been reported. Our research group has shown that the turbidimetric assay presents higher sensitivity and rapidity than traditional agar diffusion assays. The first advantage of using turbidimetric assay methods is related to the use of liquid medium, in that the solution under analysis diffuses completely, and therefore responds to lower concentrations of the antimicrobial agent. Moreover, the duration of this type of analysis is short owing to incubation period-this method requires only $4 \mathrm{~h}$ of incubation, whereas diffusion in agar requires $21 \mathrm{~h}$ of incubation [31]. The aim of this study was to validate a turbidimetric microbiological method to evaluate the mean percentage of FA in a dermatological cream.

Moreover, the reversed phase-liquid chromatography (RP-LC) method, developed and validated previously by our study group, was chosen as a comparative method in the determination of this drug.

\section{Experimental}

\subsection{Chemical and reagents}

The fusidic acid reference standard (FA-RS), with a stated purity 


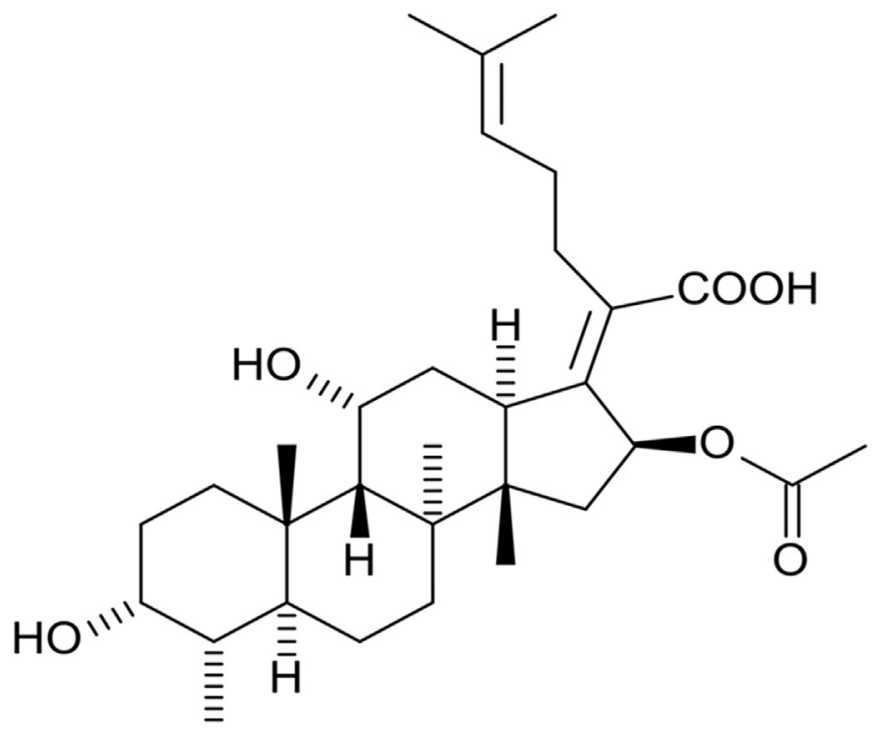

Fig. 1. Chemical structure of fusidic acid (CAS: 6990-06-3).

of $100 \%$, was purchased commercially from Sigma-Aldrich (Brazil), and a sample of dermatological cream (Verutex ${ }^{\mathrm{TM}}$ ) containing FA, with $20 \mathrm{mg} \mathrm{g}^{-1}$ of the active ingredient, was supplied by LEO Pharma Laboratory (Itapevi-SP, Brazil). All adjuvants used in the production of the formulation without the active ingredient (placebo) were of analytical grade: hydrochloric acid (Lab Synth), cetyl alcohol (Audaz), butylated hydroxyanisole (Sigma-Aldrich), glycerol (Ely Martins), white petrolatum (Tec-Lab), liquid petrolatum (Columbia), polysorbate 60 (LabSynth), and potassium sorbate (Rica Nata). The culture medium casoy broth (Oxoid, England), brain heart infusion (BHI, Merck, Germany) broth, and MuellerHinton (Acumedia, USA) were used. Analytical-grade formaldehyde (Qhemis, Brazil) was used to interrupt the growth of microorganisms. The solutions were prepared with ethylic alcohol (LabSynth) and ultrapure water (Milli- $\mathrm{Q}^{\mathrm{TM}}$ ).

\subsection{Apparatus and microbiological conditions}

For the turbidimetric assay, the culture media were weighed using a semi-analytical balance model B160 (Micronal ${ }^{\mathrm{TM}}$, SP, Brazil) and were sterilized before use in a vertical autoclave AV model (Phoenix Luferco ${ }^{\mathrm{TM}}, \mathrm{SP}$, Brazil). The microorganisms were incubated in a Shaker incubator MA420 model (Marconiт, SP, Brazil) and an oven (ECB Digital 1.2; (Odontobrás ${ }^{\mathrm{TM}}$, SP, Brazil). A spectrophotometer DU 530 (Beckman Coulter ${ }^{\mathrm{TM}}$, CA, USA) was used to determine absorbance. Calibration curves were constructed using Microsoft Excel (2010). Other apparatuses used were an ultrasonic bath (Unique ${ }^{\mathrm{TM}}$ ) and an analytical balance model H10-Class I (Mettler Toledo, Switzerland) to weigh the samples. Microbiological test was performed using FA of concentrations $0.25,0.75$, and $2.25 \mu \mathrm{g} \mathrm{mL}^{-1}$ and $6 \%$ of the microorganism S. epidermidis (ATCC 12228) in broth culture medium casoy.

\subsection{Preparation of the standard solution of FA}

The stock solution was prepared by weighing $12.5 \mathrm{mg}$ of FA-RS accurately, transferring to a $50-\mathrm{mL}$ volumetric flask, and diluting with ethanol to obtain a concentration of $250 \mu \mathrm{g} \mathrm{mL}^{-1}$. This solution was further diluted with ethanol in a $50-\mathrm{mL}$ volumetric flask to obtain a concentration of $25 \mu \mathrm{g} \mathrm{mL} \mathrm{m}^{-1}$. Aliquots of 250,750 , and $2250 \mu \mathrm{L}$ of this solution were transferred to $25-\mathrm{mL}$ volumetric flasks, and the volume was made up with ultrapure water to obtain working solutions of $0.25,0.75$, and $2.25 \mu \mathrm{g} \mathrm{mL}^{-1}$, which were designated $S_{1}, S_{2}$, and $S_{3}$, respectively, in the bioassay.

\subsection{Preparation of sample solution of dermatological cream}

To prepare the sample stock solution, $0.625 \mathrm{~g}$ of cream was accurately weighed, added to ethanol, and subjected to ultrasound. After $15 \mathrm{~min}$, this solution was transferred to a $50-\mathrm{mL}$ volumetric flask, and the volume was made up with ethanol to obtain a solution with a concentration of $250 \mu \mathrm{g} \mathrm{mL} \mathrm{m}^{-1}$. This solution was diluted with ethanol in $50-\mathrm{mL}$ volumetric flask to obtain a concentration of $25 \mu \mathrm{g} \mathrm{mL}^{-1}$. Aliquots of 250,750 , and $2250 \mu \mathrm{L}$ were transferred to $25-\mathrm{mL}$ volumetric flasks, and the volumes were made up with ultrapure water to obtain working solutions with concentrations of $0.25,0.75$, and $2.25 \mu \mathrm{g} \mathrm{mL}^{-1}$, which were designated $T_{1}, T_{2}$ and $T_{3}$, respectively, in the assay.

\subsection{Preparation of placebo solutions}

In accordance with Aulton [36] principle, a formulation with no active ingredient (placebo) was developed. The stock placebo solution was prepared in the same manner as the sample (Section $2.4)$, but without the active ingredient, FA $(12.5 \mathrm{mg})$. Aliquots of $2250 \mu \mathrm{L}$ of this solution were transferred to $25-\mathrm{mL}$ volumetric flasks, and the volume was made up with ultrapure water to simulate the highest concentration used in the assay $\left(2.25 \mu \mathrm{g} \mathrm{mL}^{-1}\right)$.

\subsection{Preparation of culture medium}

Culture media were prepared in accordance with the manufacturers' guidelines: dissolved in water under heating, distributed in test tubes $(10 \mathrm{~mL})$, and autoclaved at $121^{\circ} \mathrm{C}$ for $15 \mathrm{~min}$. After autoclaving, the tubes were cooled and immediately used in the bioassay.

\subsection{Turbidimetric assay}

The turbidimetric assay was performed in accordance with the official compendia [31,32]. For the preparation and standardization of inoculum, the S. epidermidis strain (ATCC 12228) was cultivated and maintained in tryptic soy agar medium in a freezer. The strain was inoculated with a platinum loop in casoy broth and maintained in an oven at $35 \pm 2{ }^{\circ} \mathrm{C}$ for $24 \mathrm{~h}$ before the assay, for the growth of test microorganism.

Thereafter, the procedure of standardization of the inoculum was performed: S. epidermidis previously incubated in casoy broth were diluted with pure casoy broth to achieve a suspension turbidity of $25 \pm 2 \%$ (transmittance), using a spectrophotometer at $580 \mathrm{~nm}$ with a $10-\mathrm{mm}$ absorption cell, against casoy broth as a blank. The bioassay was performed using the $3 \times 3$ parallel line assay design (three doses of the standard and three doses of the sample). Six-hundred milliliters of the standardized S. epidermidis (ATCC 12228) suspension was added to six test tubes containing $10 \mathrm{~mL}$ of casoy broth. In three of these tubes $\left(\mathrm{S}_{1}, \mathrm{~S}_{2}\right.$, and $\left.\mathrm{S}_{3}\right), 200 \mu \mathrm{L}$ of the standard working solutions was added (at concentrations of $0.25,0.75$, and $2.25 \mu \mathrm{g} \mathrm{mL}^{-1}$, respectively), and in the other three $\left(T_{1}, T_{2}\right.$, and $\left.T_{3}\right)$, the same was performed with the working sample solutions. The process was performed in triplicate. Then, the test tubes were incubated in a shaker, in a water bath, at $35 \pm 2{ }^{\circ} \mathrm{C}$ for $4 \mathrm{~h}$. After the incubation period, the growth of microorganisms was interrupted by adding $500 \mu \mathrm{L}$ of $12 \%$ formaldehyde solution to each tube. Then, the spectrophotometer was reset with the test tube containing the negative control $(10 \mathrm{~mL}$ of casoy broth containing $500 \mu \mathrm{L}$ of the formaldehyde solution), and the absorbance was determined at $530 \mathrm{~nm}$ using a spectrophotometer. 


\subsection{Method development}

Preliminary tests were conducted to standardize the conditions of the microbiological turbidimetric assay, in which parameters such as solvents (ethanol, purified water, buffer solutions $\mathrm{pH}$ 6.0 and $\mathrm{pH} 8.0$ ), culture medium (casoy broth, BHI, Mueller-Hinton), microorganism (Bacillus subtilis ATCC 9372, Kocuria rhizophila ATCC 9341, S. epidermidis ATCC 12228, S. aureus ATCC 6538), concentrations of the inoculum $(1 \%, 3 \%, 4 \%, 5 \%, 6 \%, 7 \%$, and $8 \%)$ and drug $(0.25,0.30,0.40,0.50,0.75,0.90,1.00,1.20,1.50,2.00,2.25$, $2.70,3.00,3.60,4.0,8.00,16.00,32.00$, and $64.00 \mu \mathrm{g} \mathrm{mL}^{-1}$ ) were evaluated.

\subsection{Method validation and mean percentage calculation}

The method was validated in accordance with the International Conference on Harmonisation (ICH) guidelines [37]. The mean percentage of FA in the dermatologic cream was calculated using the Hewitt equation [38].

\subsubsection{Linearity}

Linearity was determined by the analytical curve, plotted using the logarithm of the concentration versus the mean of the absorbance values, obtained on three different days for each concentration of FA $\left(0.25,0.75\right.$, and $\left.2.25 \mu \mathrm{g} \mathrm{mL}^{-1}\right)$. The results were analyzed by least squares, and linearity and parallelism were analyzed by analysis of variance (ANOVA).

\subsubsection{Precision}

Precision was assessed by repeatability and intermediate precision. Repeatability was verified by analyzing nine determinations covering the linear range of the method, i.e., three concentrations: low $\left(0.25 \mu \mathrm{g} \mathrm{mL}^{-1}\right)$, medium $\left(0.75 \mu \mathrm{g} \mathrm{mL}^{-1}\right)$, and high $\left(2.25 \mu \mathrm{g} \mathrm{mL}^{-1}\right)$, obtained from the calibration curve. This procedure was performed in triplicate, over a short period, on the same day and under the same experimental conditions in the same laboratory and by the same analyst. Intermediate precision, in turn, was evaluated by determining the mean percentage of FA, on three different days (inter-day) by different analysts, but under the same experimental conditions and in the same laboratory in triplicate. Both results were evaluated based on the relative standard deviation (RSD) values between the determinations.

\subsubsection{Accuracy}

Accuracy was determined by the recovery assay, in which known quantities of FA-RS were added to a known quantity of the sample dermatological cream. The accuracy of the method was evaluated in triplicate at three concentrations $\left(R_{1}=80, R_{2}=100\right.$, and $R_{3}=120 \%$ ) [37], and the percentage recoveries were calculated as determined by the Association of Official Analytical Chemists [39] (Eq. (1))

$R(\%)=\frac{C_{\mathrm{f}}-C_{\mathrm{u}}}{C_{\mathrm{a}}} \times 100$

where $C_{\mathrm{f}}$ is the total drug concentration measured after addition of the standard, $C_{\mathrm{u}}$ is the total drug concentration in the formulation, and $C_{\mathrm{a}}$ is the standard concentration added to the formulation.

\subsubsection{Selectivity}

Selectivity turbidimetric microbiological method was performed to verify if the adjuvants present in the dermatological cream formulation had inhibitory effect that interfered with the analysis, even after neutralization of potassium sorbate preservative and of the ethanol used as a solvent. ANOVA was performed to analyze the absorbances of the solution of the free analyte matrix-placebo (Section 2.5) and the absorbances of the positive control (10 $\mathrm{mL}$ of casoy broth containing $600 \mu \mathrm{L}$ inoculum - S. epidermidis $6 \%)$.

\subsubsection{Robustness}

To evaluate the robustness of the method, four parameters were varied independently: wavelength $(528 \mathrm{~nm}, 530 \mathrm{~nm}$, and $532 \mathrm{~nm})$, volume of the culture medium in the test tubes $(9.9 \mathrm{~mL}$, $10.0 \mathrm{~mL}$, and $10.1 \mathrm{~mL})$, incubation duration of the inoculum $(3 \mathrm{~h}$ $55 \mathrm{~min}, 4 \mathrm{~h} 00 \mathrm{~min}$, and $4 \mathrm{~h} 05 \mathrm{~min}$ ), and the brand of the culture medium, casoy broth (Oxoid and Acumedia). For this purpose, mean percentage of FA in the dermatological cream was determined under the different conditions proposed. The obtained responses were evaluated according to the RSD calculated among the dosages.

\subsection{RP-LC method}

RP-LC was previously developed and validated by our study group for the determination of FA in dermatological cream and was selected as the comparative method. The procedure was performed in the isocratic mode and the mobile phase consisted of acetonitrile and water $(72: 28, \mathrm{v} / \mathrm{v}), \mathrm{pH} 3.5$ adjusted with acetic acid. Chromatographic separation was conducted on an analytical column Agilent ${ }^{\mathrm{TM}}$ Zorbax Eclipse XDB $\mathrm{C}_{18}$ column $(250 \times 4.6 \mathrm{~mm}$, $5 \mu \mathrm{m})$, combined with a pre-column HPLC Metaguard $4.6 \mathrm{~mm}$ Polaris $\mathrm{C}_{18}$ PTC $5 \mathrm{U}-$ Agilent ${ }^{\mathrm{TM}}$ at room temperature $\left(25^{\circ} \mathrm{C}\right)$, at a flow rate of $1.0 \mathrm{~mL} \mathrm{~min}^{-1}$ and ultraviolet (UV) detection at $210 \mathrm{~nm}$.

\subsection{Comparison of methods}

The results of the microbiological assay were statistically compared with those obtained with the RP-LC method, by using the analysis of variance (ANOVA) to evaluate the difference between the two methods at a significance level of $5 \%$.

Chromatographic separations were conducted using a Waters ${ }^{\mathrm{TM}}$ HPLC system, equipped with a Waters 1525 binary gradient chromatography pump, Rheodyne Breeze $7725 \mathrm{i}$ manual injector, with a $20-\mu \mathrm{L}$ loop, Waters $2487 \mathrm{UV}$-vis detector, and Empower ${ }^{\mathrm{TM}}$ software, and an Agilent ${ }^{\mathrm{TM}}$ Zorbax Eclipse XDB $\mathrm{C}_{18}$ column $(250 \times 4.6 \mathrm{~mm}, 5 \mu \mathrm{m})$ combined with a pre-column HPLC Metaguard $4.6 \mathrm{~mm}$ Polaris $\mathrm{C}_{18}$ PTC $5 \mathrm{U}$ Agilent ${ }^{\mathrm{TM}}$ at room temperature $\left(25^{\circ} \mathrm{C}\right)$. The mobile phase consisted of acetonitrile and water (72:28, v/v) adjusted to $\mathrm{pH} 3.5$ with acetic acid. The flow rate was $1.0 \mathrm{~mL} \mathrm{~min}^{-1}$, detection wavelength was $210 \mathrm{~nm}$, injection volume was $20 \mu \mathrm{L}$, and retention time of fusidic acid was approximately $8 \mathrm{~min}$, as shown in Fig. 2.

\section{Results and discussion}

\subsection{Method development}

In a microbiological assay, the drug should demonstrate a significant response against the tested microorganism [13,31,32]. In this sense, different microorganisms were tested in combination at different microbiological conditions to find a suitable linear range for the quantification of FA in a dermatological cream.

In the preliminary tests, FA did not show antimicrobial activity against $B$. subtilis at high drug concentrations $\left(64 \mu \mathrm{g} \mathrm{mL}^{-1}\right)$ and low inoculum concentrations (1\%). However, K. rhizophila did not show significant growth in any of the three culture media.

Strains of $S$. aureus showed linear responses, with appropriate correlation between FA concentration and its inhibitory action on 


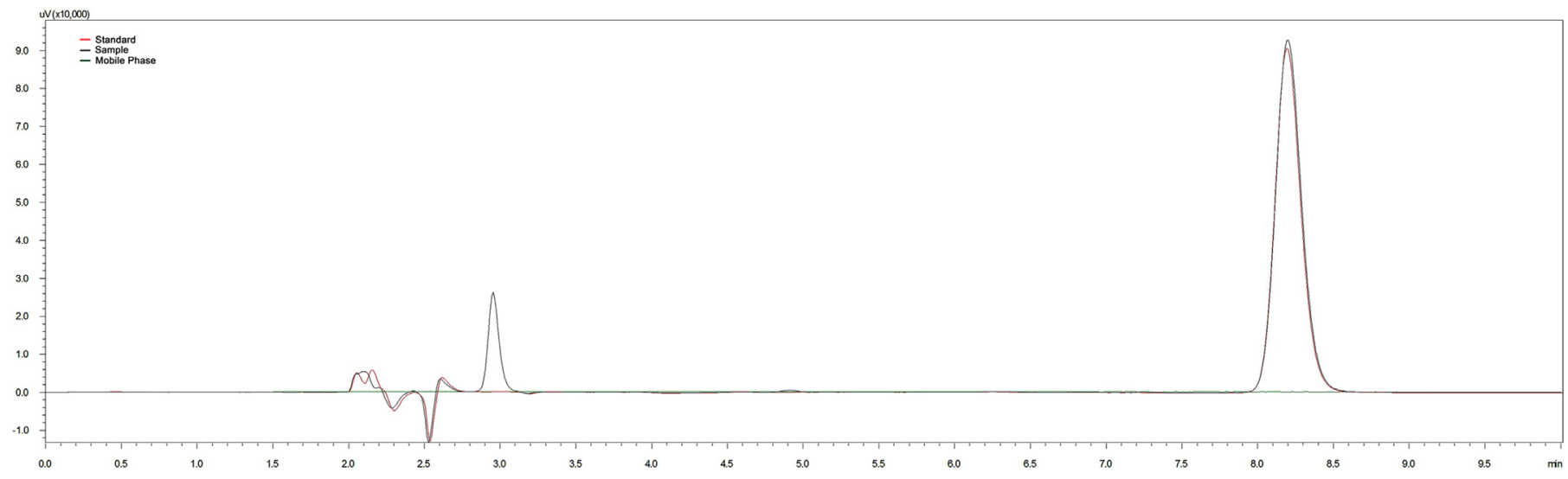

Fig. 2. Overlay of chromatograms of fusidic acid reference standard (standard), dermatological cream (sample), and mobile phase.

Table 1

Absorbance values determined by the microbiological turbidimetric assay for construction of the analytical curve of fusidic acid.

\begin{tabular}{|c|c|c|c|c|c|c|}
\hline & FA-RS $1\left(0.25 \mu \mathrm{g} \mathrm{mL}^{-1}\right)$ & FA-RS ${ }_{2}\left(0.75 \mu \mathrm{g} \mathrm{mL}^{-1}\right)$ & FA-RS $3\left(2.25 \mu \mathrm{g} \mathrm{mL}^{-1}\right)$ & $\mathrm{FP}_{1}\left(0.25 \mu \mathrm{g} \mathrm{mL}^{-1}\right)$ & $\mathrm{FP}_{2}\left(0.75 \mu \mathrm{g} \mathrm{mL}^{-1}\right)$ & $\mathrm{FP}_{3}\left(2.25 \mu \mathrm{g} \mathrm{mL}^{-1}\right)$ \\
\hline Analysis 1 & 0.427 & 0.331 & 0.234 & 0.424 & 0.325 & 0.231 \\
\hline Analysis 2 & 0.439 & 0.333 & 0.236 & 0.431 & 0.329 & 0.234 \\
\hline Analysis 3 & 0.415 & 0.328 & 0.240 & 0.411 & 0.322 & 0.242 \\
\hline Mean & 0.427 & 0.331 & 0.236 & 0.422 & 0.325 & 0.235 \\
\hline RSD (\%) & 2.73 & 0.81 & 1.37 & 2.46 & 1.03 & 2.40 \\
\hline
\end{tabular}

FA-RS: Fusidic acid reference standard; RSD: relative standard deviation; FP: finished product.

the microorganism. However, we opted for the microorganism $S$. epidermidis, since it showed high sensitivity to the drug, excellent reproducibility, and adequate linearity, besides being a microorganism of low pathogenicity. Among the various inoculum concentrations tested, the concentration of $6 \%$ showed the best results, with desirable growth of microorganism, and the concentrations of $0.25,0.75$, and $2.25 \mu \mathrm{g} \mathrm{mL}^{-1}$ of FA showed good linearity and accuracy.

Buffer solutions were not suitable for the extraction of FA from dermatological cream; thus, ethanol was used for the preparation of stock solutions and ultrapure water was used to prepare working solutions. Regarding the use of ethanol, it is known that this solvent promotes the inhibition of bacterial growth; however, this inhibition was neutralized by dilution, similar to the potassium sorbate preservative present in the formulation of the finished product [31]. The BHI broth and casoy culture medium promoted satisfactory and similar growth for all microorganisms, and the casoy broth was selected because its cost was lower than that of other media.

\subsection{Method validation}

\subsubsection{Linearity}

The drug showed linear response at concentrations between 0.25 and $2.25 \mu \mathrm{g} \mathrm{mL}^{-1}$. The representative equation and correlation coefficients $(r)$ for FA-RS and the sample of the dermatologic cream were $y=-0.087 \ln (x)+0.3065(r=1.0)$ and $y=-0.085 \ln$ $(x)+0.3031(r=0.9997)$, respectively. The values of $r$ were considered highly significant for the method. In the parallel-line model, two curves were constructed, one for FA-RS and the other for the sample of dermatological cream. The results were analyzed by analysis of variance (ANOVA), at significance level of 5\%. The method showed linearity and did not deviate from parallelism, as shown in Tables 1 and 2.
Table 2

Statistical analysis (ANOVA) of the mean values of the absorbance determined by the microbiological turbidimetric assay to construct the analytical curve of fusidic acid.

\begin{tabular}{llllll}
\hline Sources of variation & df & SS & QM & $\boldsymbol{F}_{\text {calculated }}$ & $\boldsymbol{F}_{\text {critical }}$ \\
\hline Preparation & 1 & 0.0001 & 0.0001 & 1.54 & 4.96 \\
Regression & 1 & 0.1066 & 0.1066 & $2408.93^{*}$ & 4.96 \\
Parallelism & 1 & 0.0000 & 0.0000 & 0.26 & 4.96 \\
Quadratic & 1 & 0.0000 & 0.0000 & 0.44 & 4.96 \\
Squared difference & 1 & 0.0000 & 0.0000 & 0.18 & 4.96 \\
Between doses & 5 & 0.11 & 0.02 & $482.27^{*}$ & 3.33 \\
Between tubes & 2 & 0.00 & 0.00 & 1.88 & 4.10 \\
In (error) & 10 & 0.00 & 0.00 & - & - \\
Total & 17 & 0.11 & - & - & - \\
\hline
\end{tabular}

df: Degrees of freedom; QM: Quadratic means; SS: Sum of squares.

$$
{ }^{*} p<0.05 \text {. }
$$

\subsubsection{Precision}

In the test for precision by repeatability, the RSD values were $2.46 \%, 1.03 \%$, and $2.40 \%$ for $0.25,0.75$, and $2.25 \mu \mathrm{g} \mathrm{mL}^{-1}$ of FA in the dermatological cream, respectively. In the intermediate precision, the RSD value calculated from the mean percentage of FA, on different days and by different analysts was $1.52 \%$. The method showed good precision, since all RSD values were lower than $5 \%$, as recommended by the literature [37]. Thus, the lower values confirmed that the proposed method has the capacity to generate, for the same sample, reproducible results with low variation between independent assays.

\subsubsection{Accuracy}

As shown in Table 3, the percentage recoveries confirm that the method can determine with accuracy, the content of FA in dermatological cream, since the percentage of the average recovery was close to $100 \%$. 
Table 3

Accuracy of the microbiological turbidimetric assay for the quantification of fusidic acid in dermatological cream.

\begin{tabular}{llllll}
\hline $\begin{array}{l}\text { FA-RS added } \\
\left(\mu \mathbf{g ~ m L}^{-\mathbf{1}}\right)\end{array}$ & $\begin{array}{l}\text { FA-RS found } \\
\left(\boldsymbol{\mu} \mathbf{g ~ m L}^{-\mathbf{1}}\right)\end{array}$ & Recovery (\%) & Mean (\%) $\mathbf{S D}^{\mathrm{b}}$ \\
\hline $\boldsymbol{R}_{\mathbf{1}}$ & 0.60 & 0.63 & 102.54 & & \\
$\boldsymbol{R}_{\mathbf{2}}$ & 0.75 & 0.79 & 103.84 & 101.95 & 0.90 \\
$\boldsymbol{R}_{\mathbf{3}}$ & 0.90 & 0.94 & 99.47 & & \\
\hline
\end{tabular}

a Mean of three determinations.

b Standard deviation.

Table 4

Robustness of the microbiological turbidimetric assay for the quantification of fusidic acid in dermatological cream.

\begin{tabular}{|c|c|c|c|c|}
\hline Variable & Parameters & $\begin{array}{l}\text { Mean percen- } \\
\text { tage (\%) }\end{array}$ & Mean & $\mathbf{R S D}^{\mathrm{a}}(\%)$ \\
\hline \multirow[t]{3}{*}{ Wavelength (nm) } & 528 & 103.05 & \multirow[t]{3}{*}{103.93} & \multirow[t]{3}{*}{0.77} \\
\hline & 530 & 104.13 & & \\
\hline & 532 & 104.61 & & \\
\hline \multirow{3}{*}{$\begin{array}{l}\text { Volume of culture medium } \\
(\mathrm{mL})\end{array}$} & 9.9 & 99.73 & \multirow[t]{3}{*}{103.50} & \multirow[t]{3}{*}{3.47} \\
\hline & 10.0 & 103.89 & & \\
\hline & 10.1 & 106.88 & & \\
\hline \multirow{3}{*}{$\begin{array}{l}\text { Incubation time for Sta- } \\
\text { phylococcus epidermidis }\end{array}$} & $3 \mathrm{~h} 55 \mathrm{~min}$ & 99.86 & \multirow[t]{3}{*}{103.20} & \multirow[t]{3}{*}{2.96} \\
\hline & $4 \mathrm{~h} 00 \mathrm{~min}$ & 103.84 & & \\
\hline & $4 \mathrm{~h} 05 \mathrm{~min}$ & 105.88 & & \\
\hline \multirow[t]{2}{*}{ Brand of casoy broth } & Oxoid & 103.91 & \multirow[t]{2}{*}{104.74} & \multirow[t]{2}{*}{1.13} \\
\hline & Acumedia & 105.58 & & \\
\hline
\end{tabular}

a Relative standard deviation.

\subsubsection{Selectivity}

The adjuvants in the formulation cream did not interfere with the quantification of FA, since the mean absorbance of the placebo solution (0.512) did not differ significantly (significance level of $5 \%$ ) from the mean absorbance of the positive control (0.523), where the $p$-value was 0.06468 , indicating the selectivity of the method.

\subsubsection{Robustness}

The results of the robustness of the method are presented in Table 4 . The RSD values obtained were less than $5 \%$, highlighting the robustness of the turbidimetric assay for the analysis of FA in the sample.

\subsection{Comparison of the methods}

The comparative analysis of methods is an artifice used to verify whether the procedures can be interchangeable. In this sense, the results should be sufficient to prove their equivalence at a certain range [32]. To compare the proposed microbiological method and physicochemical method of RP-LC, the mean percentage and average contents of FA in the dermatological cream, obtained by both methods were analyzed, respectively. The percentages of FA content determined by both methods were $104.00 \%$ (RP-LC) and 104.60\% (microbiological method). Statistical analysis indicated that the values did not differ significantly, because the $p$ value $(0.2995)$ was higher than $0.05 \%$ at significance level of $5 \%$.

Thus, the results obtained in this study were satisfactory, and the amount of FA calculated by both methods was within the range of $90-110 \%$ specified in the British Pharmacopoeia [13]. Despite the statistical analysis indicating that the methods are equivalent and suitable for the quantification of FA in dermatological cream, it is necessary to highlight that there are differences between these methods.

The RP-LC method is widely used by pharmaceutical companies, since it is practical and can accurately determine degradation products and impurities in the matrix. However, it requires costly equipment, analytical columns, and organic solvents as constituents of the mobile phase; therefore, maintenance of the system is costly and leads to environmental contamination. In addition, a physical-chemical method may not indicate the true biological activity of the antibacterial. It is known that the results obtained in microbiological tests and those obtained in physicalchemical methods may be different. Accordingly, for the analysis of antibiotics, such as AF, it is recommended that physical-chemical methods are performed in parallel with microbiological assays to ensure reliable results regarding their therapeutic efficacy.

Furthermore, the turbidimetric assay is a technique that does not use organic solvents and thereby does not generate chemical waste to the environment. However, this method requires a longer runtime than the RP-LC method, but the analysis time required for the microbiological turbidimetric assay is shorter than that for the agar diffusion assay currently used for the analysis of FA.

\section{Conclusion}

Taken together, the proposed method has met all the requirements set out in the international guideline, proving to be linear, precise, selective, accurate, and robust. Furthermore, statistical analysis (ANOVA) showed that the proposed turbidimetric assay and the RP-LC method developed and validated by our study group did not differ significantly. At the same time, the turbidimetric assay allows determination of the true biological activity of FA, when compared with physical-chemical methods, such as LC.

Further, this method involves simple and rapid procedures of sample preparation, without generating toxic waste to the environment. In addition, it is safe for the operator, since the microorganism used is not considered pathogenic. In this sense, the validated method can quantify FA in dermatological cream in a reliable and secure way for quality control; therefore, it is an alternative method to the diffusion agar assay.

\section{Acknowledgment}

We are very grateful to the lab of LEO Pharma (Itapevi-SP, Brazil) for donating the medicine and FAPESP (Fundação de Amparo à Pesquisa do Estado de São Paulo, Brazil, Project 2013/ 02861-3) for financial support.

\section{References}

[1] W.O. Godtfredsen, S. Vangedal, The structure of fusidic acid, Tetrahedron 18 (1962) 1029-1048.

[2] J.D. Wilkinson, Fusidic acid in dermatology, Br. J. Dermatol. 139 (1988) 37-40.

[3] M.E. Falagas, P. Kopterides, Old antibiotics for infections in critically ill patients, Curr. Opin. Crit. Care 13 (2007) 592-597.

[4] J.D. Anderson, Fusidic acid: new opportunities with an old antibiotic, Can. Med. Assoc. J. 122 (1980) 765-769.

[5] R.N. Jones, R.E. Mendes, H.S. Sader, M. Castanheira, In vitro antimicrobial findings for fusidic acid tested against contemporary (2008-2009) Gram-positive organisms collected in the United States, Clin. Infect. Dis. 52 (2011) S477-S486.

[6] D. Spelman, Fusidic acid in skin and soft tissue infections, Int. J. Antimicrob. Agents 12 (1999) S59-S66.

[7] S. Vladimirov, Z. Fiser, D. Agbaba, D. Zivanov-Stakic, Spectrophotometric determination of fusidic acid and sodium fusidate in dosage forms, J. Pharm. Biomed. Anal. 13 (1995) 675-678.

[8] D.E. Satarova, V.B. Korchagin, V.V. Stepushkina, R.A. Makarova, Spectrophotometric method for determination of fusidic acid, Antibiot. Khimioterapiia 34 (1989) 566-569.

[9] S.M. Hassan, S.M. Amer, M.M. Amer, Determination of fusidic acid and sodium fusidate in pharmaceutical dosage forms by first-derivative ultraviolet spectrophotometry, Analyst 112 (1987) 1459-1461.

[10] A. Carlstrom, K. Dornbusch, A. Hagelberg, Use of electrophoresis in the 
identification and quantitation of antibiotics administered in combinations, Scand. J. Infect. Dis. 9 (1977) 46-54.

[11] J. Morgan, M.E. Joyce-Menekse, R.T. Rowlands, I.H. Gilbert, D. Lloyd, Rapid and sensitive quantitation of antibiotics in fermentations by electrospray mass spectrometry, Rapid Commun. Mass Spectrom. 15 (2001) 1229-1238.

[12] N.H. Al-Shaalan, Atomic absorption spectrometric determination of fusidic acid in bulk powder and in pharmaceutical dosage form, J. Chem. Pharm. Res. 2 (2010) 135-143.

[13] British Pharmacopoeia, London: The Stationary Office, v. 1, p. 964; v. 3, pp. 2724-2727, 2010.

[14] European Pharmacopoeia, 7th. ed. Strasbourg: Council of Europe, v. 2, pp. 2079-2080, 2010.

[15] J. Krzek, U. Hubicka, J. Szczepanczyk, A. Kwiecien, W. Rzeszutko, Simultaneous determination of fusidic acid, $m$ - and $p$-hydroxybenzoates and butylhydroxyanisole by TLC with densitometric detection in UV, J. Liq. Chromatogr. Relat. Technol. 29 (2006) 2129-2139.

[16] J. Byrne, T. Velasco-Torrijosb, R. Reinhardt, Development and validation of a novel stability-indicating HPLC method for the simultaneous assay of betamethasone-17-valerate, fusidic acid, potassium sorbate, methylparaben and propylparaben in a topical cream preparation, J. Pharm. Biomed. Anal. 5 (2014) $111-117$.

[17] M. Nawaz, M.S. Arayne, N. Sultana, A. Haider, S. Hisaindee, Simultaneous determination of fusidic acid and steroids from bulk drugs and human plasma by reversed phase HPLC, Acta Chromatogr. 26 (2014) 57-66.

[18] N. Goswami, V.R.M. Gupta, A.H. Jogia, Development and validation of a novel stability-indicating RP-HPLC method for the simultaneous determination of halometasone, fusidic acid, methylparaben, and propylparaben in topical pharmaceutical formulation, Sci. Pharm. 81 (2013) 505-518.

[19] C. Hong, Z. Rong, Determination of dexamethasone acetate and fusidic acid in compound dexamethasone and fusidic acid cream, Chin, J. Antibiot. 37 (2012) 924-926.

[20] R. Ankam, K. Mukkanti, S. Durgaprasad, P.V.L. Naidu, Simultaneous determination of halobetasol propionate and fusidic acid related substances by reversed phase high performance liquid chromatographic method, Asian J. Chem. 22 (2010) 3376-3380.

[21] C. Nianfen, W. Yandong, C. Mooling, Determination of fusidic acid ophthalmic emulsion by HPLC, China Med. Her. 22 (2009) 72-73.

[22] S. Shaikh, M.S. Muneera, O.A. Thusleem, M. Tahir, A.V. Kondaguli, A simple RP_ HPLC method for the simultaneous quantitation of chlorocresol, mometasonefuroate, and fusidic acid in creams, J. Chromatogr. Sci. 47 (2009) 178-183.

[23] K.-K. Peh, Y.T. Tan, Simple high-performance liquid chromatographic method for simultaneous determination of fusidic acid and betamethasone dipropionate in a cream formulation, Int. J. Pharm. 4 (2000) 229-231.

[24] A. Rahman, N.E. Hoffman, High-performance liquid chromatographic determination of fusidic acid in plasma, J. Chromatogr. B 433 (1988) 159-166.

[25] N.H. Sorense, Liquid chromatographic determination of fusidic acid in serum, J. Chromatogr. B 430 (1988) 400-405.

[26] A.H. Hikal, Assay of fusidic acid in plasma by high-performance liquid chromatography, Int. J. Pharm. 13 (1983) 297-301.

[27] A.H. Hikal, A. Shibl, S. El-Hoofy, Determinations of sodium fusidate and fusidic acid in dosage forms by high-performance liquid chromatography and a microbiological method, J. Pharm. Sci. 71 (1982) 1297-1298.

[28] E.M. Costi, M.D. Sicilia, S. Rubio, D. Perez-Bendito, Quantitation of fusidane antibiotics in pharmaceuticals using the surfactant-dye binding degree method, Anal. Chim. Acta 549 (2005) 159-165.

[29] F.R. Lourenço, M.A.L. Traple, R.T. Okamoto, T.J.A. Pinto, Development and validation of microbiological assay for ceftriaxone and its application in photostability study, Curr. Pharm. Anal. 9 (2013) 77-81.

[30] A.S.L. Mendez, V. Weisheimer, T.P. Oppe, M. Steppe, E.E.S. Schapoval, Microbiological assay for the determination of meropenem in pharmaceutical dosage form, J. Pharm. Biomed. Anal. 37 (2005) 649-653.

[31] Brazilian Pharmacopoeia, 5th. ed. Brasília: Anvisa 2010.

[32] USP, The United States Pharmacopoeia, The United States Pharmacopoeial Convention, Rockville, 37th ed, 2014

[33] I. Bartoshevich, A.A. Egorov, V.L. Gol'dshtein, I.J. Jones, P.A. Luni, Utilization of automatic systems for determining the biological activity of antibiotics by the agar diffusion method, Antibiotiki 21 (1976) 122-127.

[34] V.G. Koroleva, Agar-diffusion method for determination of fusidin in body fluids and tissues, Antibiotiki 16 (1971) 727-729.

[35] Y. Kanazawa, T. Kuramata, Fusidic acid. Assay for microbiologically active concentration in body fluids and sensitivity test by agar diffusion, J. Antibiot. 17 (1964) 7-11.

[36] E.M. Aulton, Delineamento de Formas Farmacêuticas, 2 ed., Artmed, Porto Alegre, 2005.

[37] ICH, Harmonised tripartite guideline, Validation of analytical procedures: text and methodology-Q2(R1). Proceedings of International Conference on Harmonisation, Geneva, The Switzerland, November, 2005.

[38] W. Hewitt, Microbiological Assay for Pharmaceutical Analysis: A Rational Approach, Interpharm/CRC, Boca Raton, FL, USA, 2003.

[39] AOAC, Association of Official Analytical Chemists, Official methods of analysis, 18th ed., Gaithersburg, MD, 2005. 